\title{
Multiple Referral and U.S. House Legislative Success in the 1990s
}

\author{
Glen S. Krutz and Courtney L. Cullison
}

We examine the impact of multiple referral on legislative processing in the U.S. House of Representatives from 1991-98. Previous literature leaves off with the 1980s, but party control of the House changed in the 1990s and with it, came a new approach to multiple referral. Did this change alter the impact of multiple referral status on bill progression? In the main, our analysis confirms certain previous findings, while adding some interesting new twists. While multiple referral hurts a bill's chances of success in some stages of statute-making (committee passage, floor passage), a finding consistent with the literature, we find that it provides a boost to chances of receiving committee attention in the first place. Moreover, we find that the hit that multiply-referred bills take in committee and on the floor is much greater than suggested previously. Separate analyses conducted before and after the Republican reforms of 1995 reveal distinct differences. For example, in the Republican-controlled environment from 1995-1998, multiple referral bills were slightly more likely to see the House floor, whereas they were less likely to make it in the Democratic House from 1991-94.

The ability for the Speaker (and Parliamentarians) to refer bills to more than one committee was among the most visible changes enacted during the 1970s House reforms. Reflecting the tendency of House committees to increasingly share issue jurisdictions, this institutional change made sense to many. While the adoption of this reform, like many other changes across congressional history, may be logically traced to the dual goals of improving congressional capacity and appeasing power bases in the committee system (King 1997; Schickler 2001; Smith 1989), understanding the impact of multiple referral is less obvious. On the one hand, it induces committees to share expertise on bills that pertain to more than one committee, which could lead to cooperation and, hence, legislative productivity (King 1997). On the other hand, multiple referral creates more veto points for pieces of legislation as they traverse the daunting legislative process (Rieselbach 1994).

We examine the impact of referral from the point at which the literature leaves off-the always fascinating 1990s, which featured three different Speakers and a return to Republican rule. After reviewing the state of the literature on multiple referral, we discuss our design and method. We then

\footnotetext{
We thank the Political Science Department and the Carl Albert Center at The University of Oklahoma for the general support provided for this study. Stanley Bach, Gary Copeland, Michael Givel, Paul Goren, Patrick Kenney and Cindy Simon Rosenthal provided helpful comments on this subject. We also thank the Editor and three very thorough anonymous reviewers.
}

GLEN S. KRUTZ is the associate director of the Carl Albert Congressional Research and Studies Center and an associate professor of political science at the University of Oklahoma. COURTNEY L. CULLISON is an assistant professor of political science at the University of Texas at Tyler.

The American Review of Politics, Vol. 29, Spring, 2008: 65-81

(c)2008 The American Review of Politics 
present the findings and conclude with a discussion about the implications of this institutional change.

\section{Previous Research}

The practice of referring bills to more than one committee is a relatively new procedure in the House of Representatives. First instituted as part of the 1974 overhaul of committee jurisdictions, multiple referral was intended to do several things. First, it was intended to produce better legislation by allowing for input from several different committees and bringing more individuals into the consideration of bills. In addition, it was expected that multiple referrals would encourage cooperation across committees and keep jurisdictional conflicts in check. There was also a political motive- the option of multiply referring a bill was expected to strengthen the Speakership and the Rules Committee (Davidson, Oleszek, and Kephart 1988).

Since 1975, multiple referrals have become common in the House, and, as of 1990, accounted for fifteen to twenty percent of all measures introduced and reported (Young and Cooper 1993, 213). ${ }^{1}$ This rising significance led several scholars to turn their attention to the effects of this new congressional practice. The joint result of this literature is the conclusion that multiple referrals have affected virtually all aspects of the legislative process, from committee consideration to leadership power and, finally, the success of legislation. ${ }^{2}$

\section{Committee Consideration}

Multiple referral has affected the dynamics of committee consideration. Committees now must engage in strategic actions when considering multiple committee measures, or even before a bill has been referred. A committee may choose a strategy of cooptation, seeking to limit or even negate the effect of other committees in the process. If such a strategy is chosen, it will most often take place during the drafting of the legislation. Predictably, this type of strategy increases conflict among committees, intensifying jurisdictional disputes and ultimately sounding the defeat of a measure that may have otherwise had a good chance of success (Young and Cooper 1993).

A second strategy option for a committee is cooperation. In fact, committees may even interact in a cooperative manner prior to referral. Committee and staff members may be simultaneously involved in the drafting of legislation, or may agree to some sort of pre-referral bargains. These bargains may be an agreement about what type of referral to request, or an agreement regarding which sections of the bill will be handled by each committee (Young and Cooper 1988). 
Once a bill has been formally referred by the Speaker (in reality, the Parliamentarian) and is under consideration by more than one committee, the process may follow a few different paths. Committees for which jurisdictional overlap is the norm may proceed differently than committees for which multiple committee legislation is a rarity. Committees often paired by multiple referral are most likely to develop a set of standard practices for handling legislation. Committees that do not often work together may have more divergent perspectives, and thus find it more difficult to process legislation (Davidson, Oleszek, and Kephart 1998).

Any time a committee receives a bill that has been multiply referred (regardless of the frequency of multiple referrals to the committees), it must closely monitor the other committees handling the bill. If the legislation has broad support, the general pattern is for one committee to take the lead by referring the bill to subcommittee for hearings. The other committees will hold off in their consideration until they are certain that the lead committee wishes to act on the bill (Young and Cooper 1993).

It has been observed that committees often directly communicate with each other over the course of bill consideration. This communication can prevent the duplication of effort and streamline the process of committee consideration, as well as further the reconciliation of differences of the committees. However, Young and Cooper (1993) found no evidence of greater occurrence of joint hearings as multiple referrals have become more common.

Other scholars have argued that multiple referral has undermined committee autonomy and encouraged committees to guard their territory. Though many committees have developed a set of informal norms that govern joint consideration and reduce open jurisdictional conflict, these understandings do not restore autonomy. Committees that were once free to act independently are now placed in interdependent relationships with two or more committees on a regular basis (Smith and Deering 1990).

\section{Floor Action and Conference}

Multiple committee bills can prove difficult to manage on the floor. Before such a bill can move to the floor, any differences among the committees must be ironed out with compromises, bargains, and prearranged amendment rules (Young and Cooper 1993). If a compromise cannot be reached, the Rules Committee is faced with the decision of which committee's version to bring to the floor and allowing the other committee's version to be offered as an amendment. This may result in open conflict on the floor. To avoid this potential hindrance, the Speaker or members of the Rules Committee may step in as a broker or arbitrator (Smith 1989; Young and 
Cooper 1993). This need for compromise after a bill is reported out of committee is another area where committees have lost autonomy. One committee can no longer determine the context of floor consideration; that is, a single committee may harbor less influence with the Rules Committee on a multiple committee bill.

The increase in multiple referral has also contributed to the growth of special rules. One of the most common special rules is the provision for alternative substitutes. Multiple committee bills are seven times more likely to be given such a rule, partially due to their complex and controversial nature (Smith 1989). Restrictive rules have also proved useful in the floor management of multiple committee bills. A restrictive rule can ensure protection of committee compromises, and thus committees may be more willing to make such compromises. A restrictive rule can also give committee leaders the option of leaving more controversial provisions in a bill to a floor vote without fear that the entire bill will be dismantled (Young and Cooper 1993).

Multiple referral may also affect the House beyond their passage of a bill. If a bill survives both House and Senate floor consideration, House conferees may be disadvantaged if the bill was handled by multiple committees. All committees must have some representation on the conference committee, but the actual number appointed from each House committee depends on the proportion of the bill that falls under each committee's jurisdiction. These House conferees, since they come from different committees, are less likely to form a cohesive "House" unit. In extreme cases, this may mean the breakdown of coalitions that formed around the bill during consideration on the House floor (Young and Cooper 1993). Ultimately, this may advantage the Senate in conference negotiations or lead to the failure of the bill.

\section{Leadership}

By the late 1980s, most scholars had concluded that the power of multiple referral had strengthened House leadership. Even taken alone, the act of referring a bill can have significant implications for the bill's success or failure. The Speaker is also a key player in settling differences among committees, and can set time limits on committee consideration, thus forcing a committee to act or face discharge of the bill (Smith and Deering 1990; Young and Cooper 1993).

But Speakers tend to use this power wisely. They hesitate to impose cut-off dates on committees, and most multiple referrals have no time limits. Speakers also seem to recognize that they are not the only members who have been strengthened by multiple referral. It has also enhanced the ability of committee leaders to claim new jurisdiction, and the Speaker must be 
careful in handling the jurisdictional conflicts that result from these claims (Schickler 2001).

\section{Success of Legislation: Previous Empirical Findings}

Several scholars have argued that multiple referral has served as an impediment to the legislative process. Adding more committees to the consideration of a bill has multiplied the veto points and made success less likely (Young and Cooper 1993). Others have said that multiple referrals reinforces the decentralized nature of the House and exacerbates the problems associated with such a nature (Oleszek 1996). But the same scholars also argue that the cross committee dialogue and compromise facilitated by multiple referral results in more effective problem solving and better legislation (Oleszek 1996; Young and Cooper 1993).

Beyond the process of multiple referrals, multiple committee bills may face a more difficult road to passage than bills referred to just one committee. Previous work has found that multiply-referred measures have a lesser likelihood of being reported out of committee, and thus are less likely to pass on a floor vote. This is due to the very nature of multiply-referred bills - they are generally complex, multifaceted, and raise issues that are difficult to resolve in the span of two years (Davidson, Oleszek, and Kephart 1988).

But there is also evidence that multiple referrals are not inherently doomed to failure. While multiple referrals grew as a percentage of all bills introduced in the House in the first decade of the practice, floor passage of multiply-referred measures increased as well (Davidson, Oleszek, and Kephart 1988). Perhaps there is a learning curve associated with multiple referrals and the House has begun to catch up, finding a way to deal with the complexity. John Baughman's (2006) recent work demonstrates that committees that are used to coordinating with other committees will be more conciliatory in such relations on multiply-referred legislation than will committees with more concentrated jurisdictions.

In summary, the very helpful existing literature on multiple referral effectively dissects the various, and competing, incentives involved with multiply referred bills. The practice of multiple referral may serve to improve the process of legislating in shared issue jurisdictions. Yet, at the individual bill level of analysis, multiple referral introduces additional veto points to an already arduous legislative process; hence, the evidence marshaled by Davidson, Oleszek, and Kephart (1988) that multiply-referred bills are less likely to succeed than singly-referred bills is intuitive. However, almost all of the above literature was written about multiple referral as the mechanism was utilized in the 1970s and 1980s. We seek to push the 
examination of the impact of multiple referral into the 1990s, a decade which brought dramatic change to the U.S. House of Representatives. Further, we utilize multivariate analysis to determine whether or not our bivariate findings are robust enough to survive in a multivariate setting with controls. Before discussing the findings, we describe our research design and methods.

\section{Design and Measures}

We test the impact of multiple referral status on the likelihood of bills to progress through the stages of the legislative process: hearings, committee passage, floor passage, and enactment into public law. Hence, bills are the units of analysis. The key explanatory variable is whether the bill was multiply-referred or not. ${ }^{3}$ We examine all 2,649 bills introduced from 19911998 across a sample of five issue areas: agriculture, environment, education, health care, and telecommunications. The five issue areas were chosen to constitute a representative mix of substantive issue types, saliencies, and jurisdictional arrangements. Agriculture and education feature lower saliency on Capitol Hill (fewer hearings) and activity within mostly one committee. In contrast, environmental and health care policy are of higher saliency (many more hearings), and both issues span the jurisdiction of numerous committees. Telecommunications policy holds a middle position in this continuum. ${ }^{4}$ It is important to note that multiple referrals occur within all the policy areas (the tight concept of "iron triangles" of yesteryear is now outdated (Browne 1998)), though the propensity is higher in health care and environmental policy than in agriculture and education, as we would expect.

We obtained all of the bills introduced in these five issue areas from 1991 to 1998 from the on-line service CIS Congressional Universe (Congressional Information Service, Inc. 2003). This process yielded 2,649 bills in the House referred to a total of 25 different committees. About two-thirds of the bills were referred to one House committee ( $66.3 \%$ or 1,757 bills). Roughly one-third $(33.7 \%$ or 892 bills) were multiply-referred. Of the multiply-referred bills, 60.7 percent (or 541 bills) were referred to two committees and 25.6 percent ( 228 bills) to three committees. Of the multiplyreferred bills, 8.4 percent were referred to four committees, 2.6 percent to five committees and 1 percent each to six and seven committees. One bill was referred to eight committees and five bills $(.6 \%$ of those multiplyreferred) were sent to nine committees! Figure 1 displays the proportion of multiply-referred to singly-referred bills across the four Congresses from 1991-98. The level of multiple referrals stays roughly the same across the decade: about one third. We next turn to our bivariate and multivariate findings of the impact of referral status on legislative progression. 
Figure 1. Multiple Referral Usage by Congress, U.S. House, 1991-98

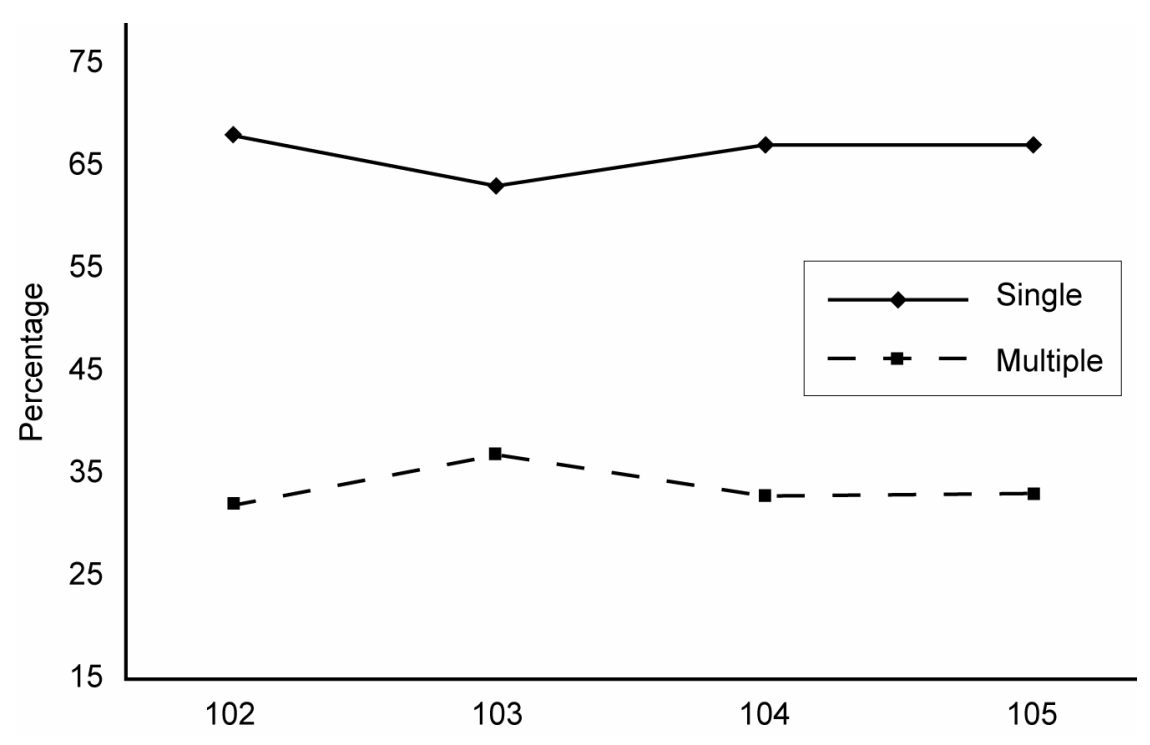

\section{Findings}

Figure 2 tracks the percentage of bills passing each stage by type of referral and includes all bills referred as the denominator at each stage. That is, each stage reflects a percentage that progresses among all the bills referred to committee. This is the approach taken by previous scholars (Davidson, Oleszek, and Kephart 1988; and extension by Young and Cooper 1993), with the exception that we added stages for committee attention prior to committee passage and final enactment into public law. ${ }^{5}$

Looking at our entire time period of 1991-98, our findings for the committee reported and floor passage stages are consistent with previous work. Singly-referred bills are slightly more likely than multiply-referred bills of progressing through these stages. Fully 10 percent of singly-referred bills are reported out of committee, while about 8 percent of multiply-referred bills make it. Our addition of the public law stages also corroborates the trend that multiply-referred bills are slightly less likely to succeed $(3.6 \%$ singlereferrals make it, while just $1.8 \%$ multiples become law). In contrast, multiple referral status actually helps bills survive the initial cut of the legislative process. Multiply-referred bills gain hearings 16.5 percent of the time, while singly-referred bills advance to hearings 13.3 percent of the time. This finding makes sense because bills referred to more than one committee have a higher probability that any one committee will choose to hear it than bills 
Figure 2. Percentage of Bills Passing by Stage and Type of Referral of All Bills Referred, U.S. House, 1991-98

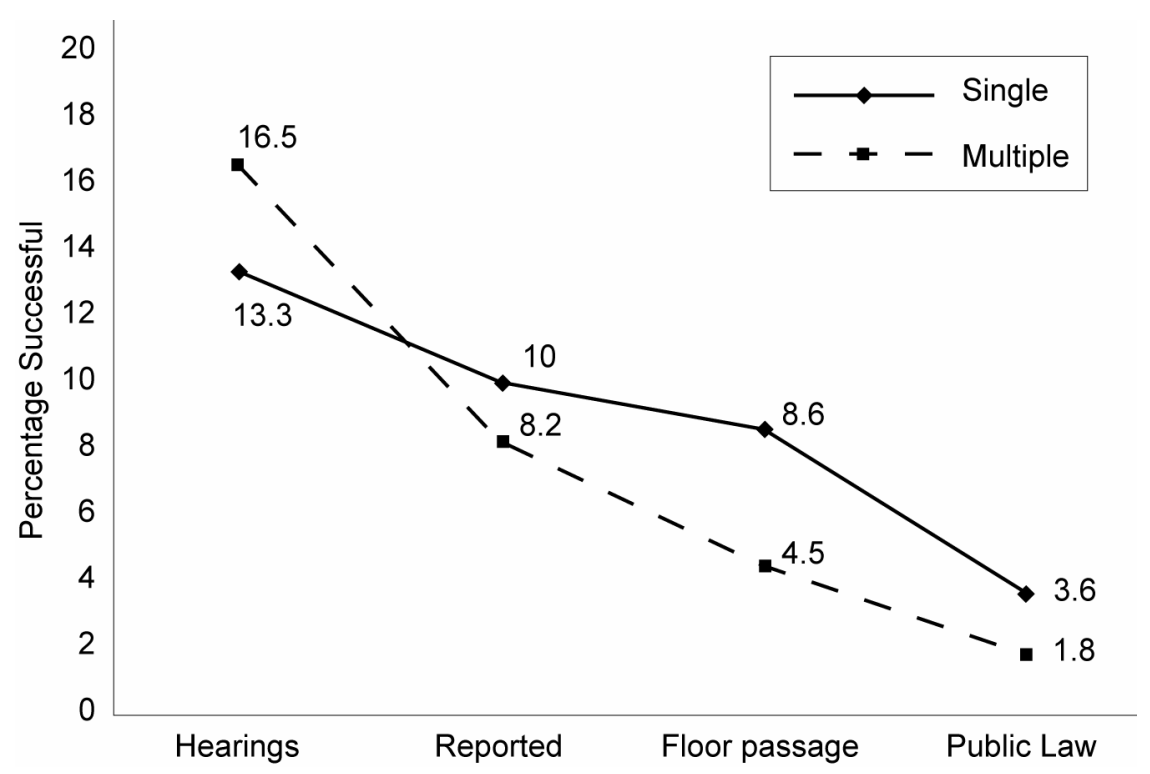

referred to only one committee. In summary, the impact of multiple referral is conditional upon the stage of the legislative process.

As we described earlier, House Republicans made changes to the multiple referral process when they took control of the House in 1995. Namely, on each such referral, a lead committee was essentially "placed in charge" of the bill as it meandered its way through the pre-floor legislative process. Figures 3 and 4 take the analysis from Figure 2 and break it down pre-and post-1995 to see if this change altered the descriptive patterns. Figure 3, which shows data from 1991-94 under Democratic control, is a mirror image of the aggregate 1991-98 trend. Multiply-referred bills are more likely to get a hearing, but less likely to pass out of committee, clear the floor, or become law. Figure 4, however, shows a notable change once Republicans won House control in the committee reported stage of the process. Under the lead-committee model, multiply-referred bills are more likely to emerge than singly-referred bills, the opposite relationship from that in Figure 3.

Our second approach to descriptive analysis also examines the percentage of bills passing each stage by type of referral, but this time we filter out the bills that did not survive the previous stage. So, the reported stage statistic is the percentage of bills reported out of committee that were heard in committee, the floor passage statistic is the percentage of bills passing the 
Figure 3. Percentage of Bills Passing by Stage and Type of Referral of All Bills Referred, U.S. House, 1991-94

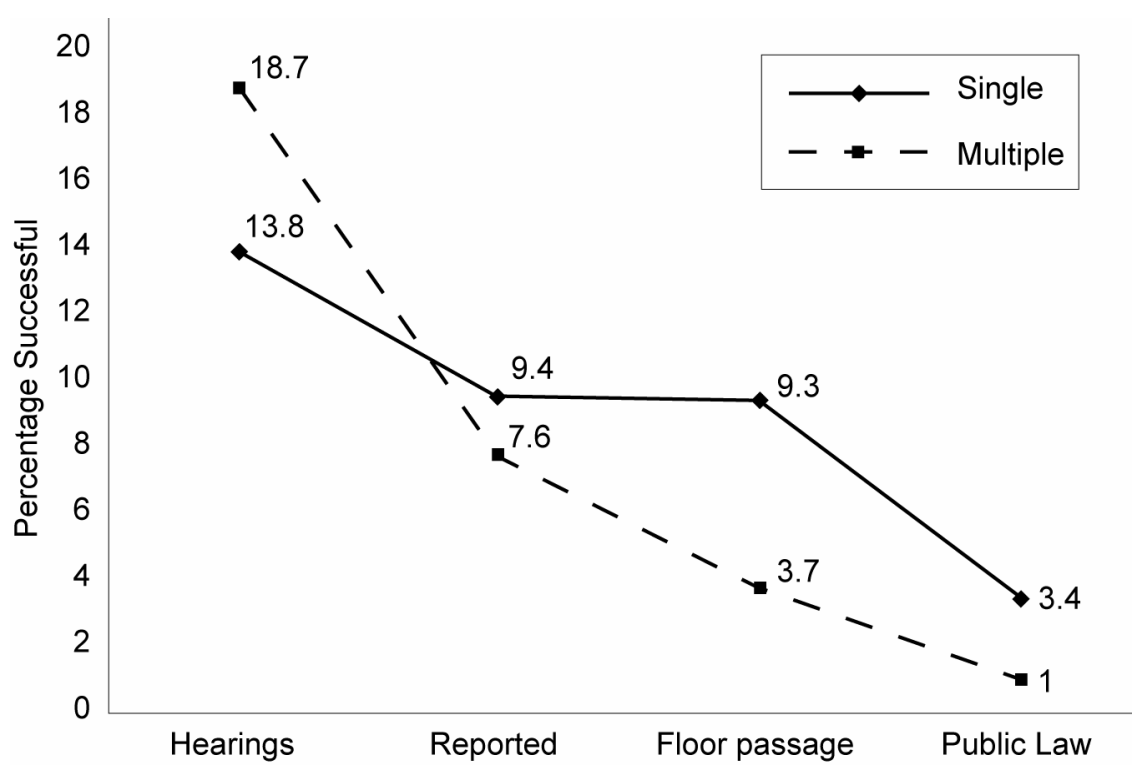

Figure 4. Percentage of Bills Passing by Stage and Type of Referral of All Bills Referred, U.S. House, 1995-98

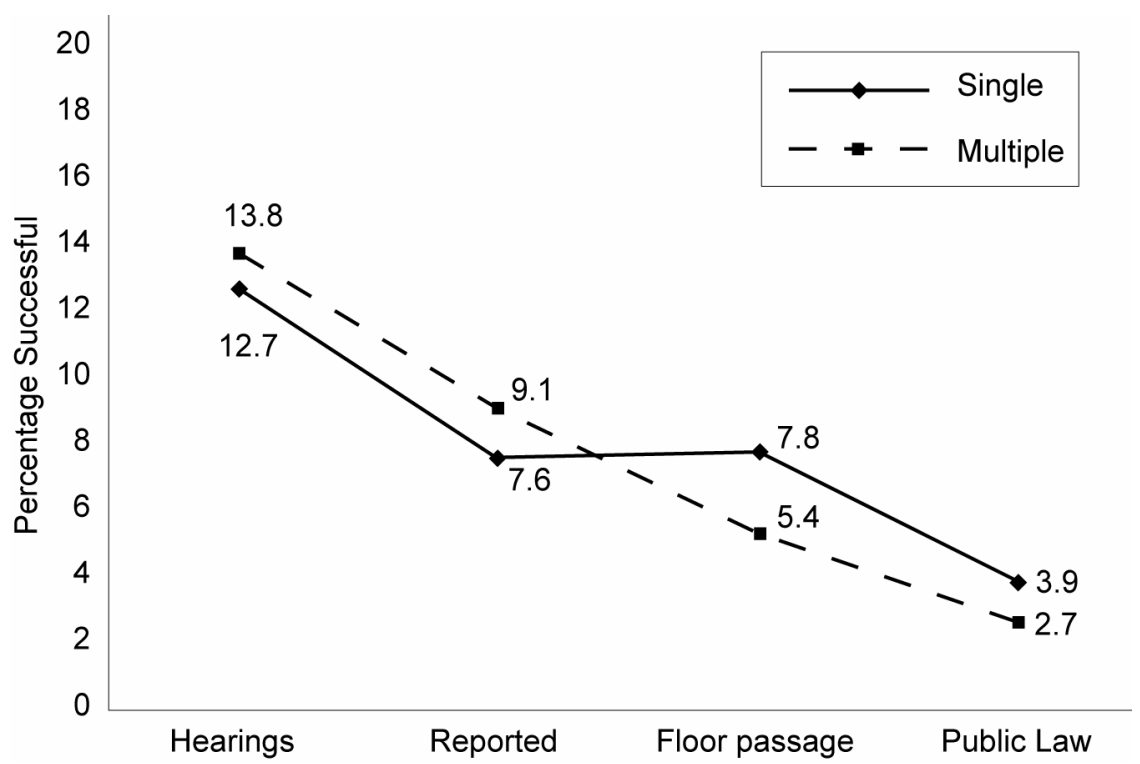


floor of those reported by committee, and the public law statistic is the percentage of bills enacted into law of those passing the House. This analytical approach we feel is a better one. It only includes the bills that actually have a chance of passing each stage. Including all bills referred for the stage success statistics, as we did in Figure 2-4 to replicate previous work, could potentially distort the results.

The findings using this approach reveal interesting differences. First, we see that the difference in the percentage of bills surviving the committee reported and floor passage stages by type of referral is much more dramatic. Of the bills heard in committee, singly-referred bills are 50 percent more likely to be reported out of committee than multiply-referred bills. The difference is even more dramatic at the floor passage stage: singly-referred bills reported out of committee are four times more likely to pass the House floor than multiply-referred bills. This finding highlights the difficulties of managing the House floor in the face of competing committees (Smith 1989). Also, the trace effect found in Figure 2 of multiple referral on enactment into public law disappears when we filter out those bills that did not pass the floor. Singly-referred bills are about equally as likely as multiply-referred measures to be enacted into public law.

As we did above, we next present separate trends for the Democratic House of 1991-94 operating under the traditional multiple referral technique separate from the Republican House of 1995-98 in which a lead committee was named for each bill. Figures 6 and 7 show the results. The Democratic trend exhibited in Figure 6 is quite similar to the overall trend from Figure 5. However, in Figure 7, a Republican difference again emerges. Namely, multiply-referred bills are slightly more likely to pass committee than singly-referred bills, a finding that stands in stark contrast to the Democratic trend when singly-referred were much more likely to pass than multiplyreferred legislation.

To make us more certain that the relationship between referral status and legislative success was not the spurious result of a bi-variate modeling approach, we created a multivariate model with controls for each legislative stage. The unit of analysis in these models is the individual bill and the dependent variable is whether or not the bill progressed through the particular stage. The control variables we incorporate along with the multiple referral variable include: whether or not the sponsor is a majority party member, the seniority of the sponsor in years, the number of co-sponsors, and the percentage of co-sponsors from one party. ${ }^{6}$ Tables 1 through 3 report the results of the multivariate analyses using logistic regression, with columns for 3 different time periods: 1991-98, 1991-94 (Democratic control), and 1995-98 (Republican control with the changed referral approach). All told, the bi-variate findings hold in a more comprehensive model with controls. 
Figure 5. Percentage of Bills Passing by Stage and Type of Referral, U.S. House, $1991-98$

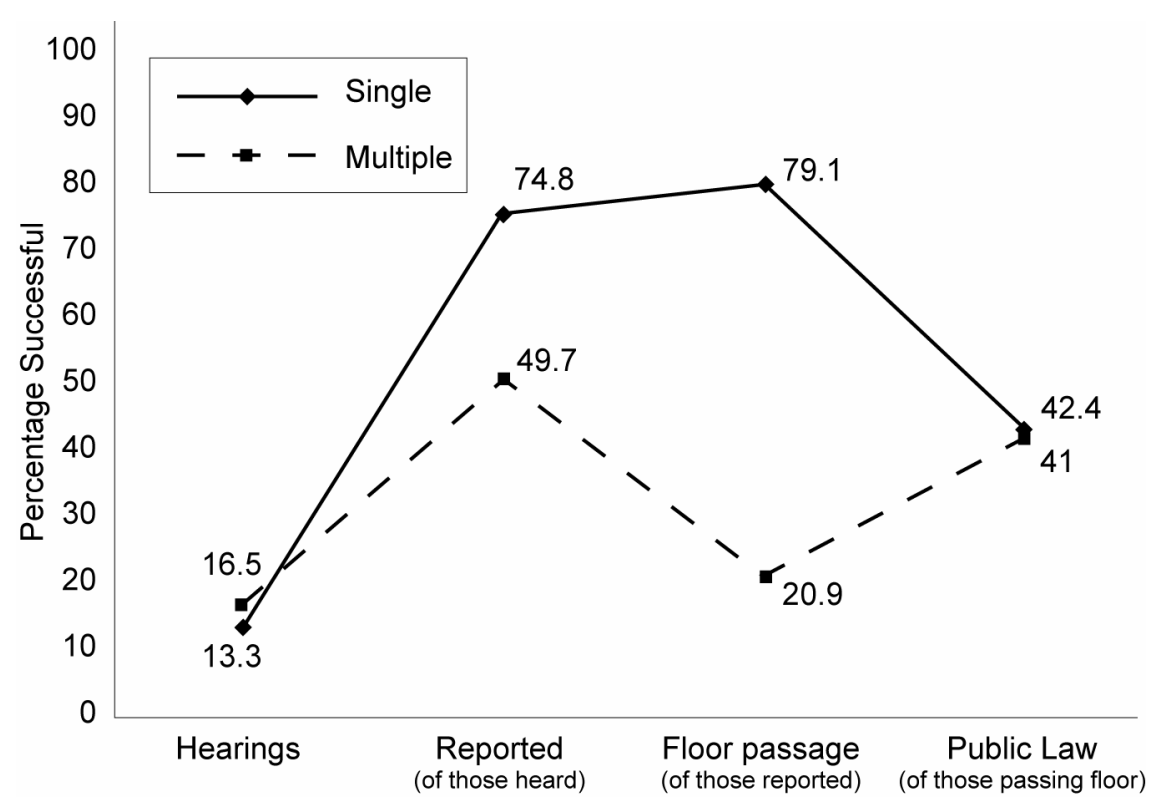

Multiply-referred bills are more likely to be heard, much mess likely to be reported, even more less likely to pass the floor, and no more or less likely to be enacted into law than singly-referred bills. ${ }^{7}$

Turning first to Table 1, which presents the results of a logit analysis of bill progression from initial referral to committee hearing, we see that in the presence of strong controls for party and sponsor intensity, multiply-referred bills are significantly more likely to move to hearing than singly-referred bills in the 1991-98 timeframe and under Democratic control. Looking at the substantive impact (in parentheses), multiply-referred bills are 5 percent and 8 percent more likely to advance. However, the multiple referral variable falls well short of significance under Republican control. In contrast to the slight substantive impact of multiple referral status on a bill's chance of progressing, the party status of the sponsor and the bi-partisan nature of the co-sponsors have much more meaningful impact. In all three models, majority sponsors are over 30 percent more likely to see their bills advance from referral to a committee hearing than are minority members. The co-sponsor party percentage variable takes a value from .50 to 1 . If the co-sponsoring coalition is perfectly split between Democrats and Republicans, the value is .50 . If the coalition is made up entirely of one party, it takes the value of 1 . 
Figure 6. Percentage of Bills Passing by Stage and Type of Referral, U.S. House, 1991-94

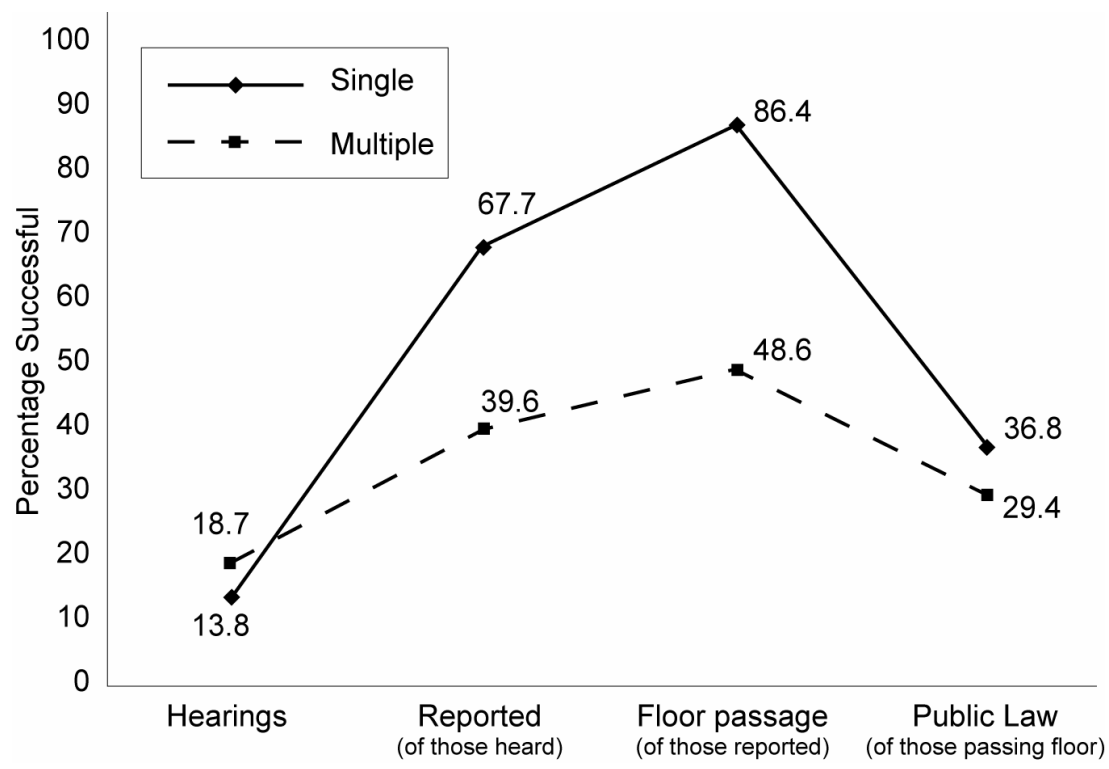

Figure 7. Percentage of Bills Passing by Stage and Type of Referral, U.S. House, 1995-98

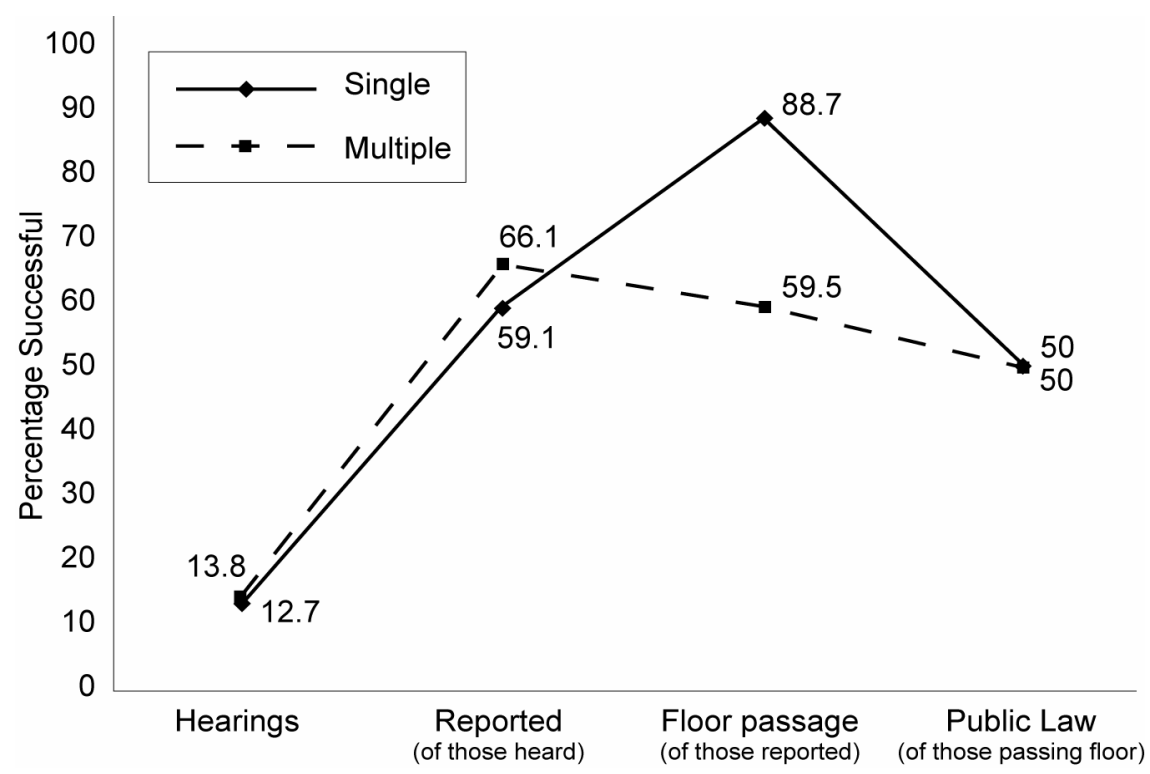




\section{Table 1. Logit Analysis of the Determinants of Bill Progression from Referral to Committee Hearing, U.S. House}

\begin{tabular}{lccc}
\hline & $1991-98$ & $1991-94$ & $1995-98$ \\
Independent Variable & $\mathrm{B}(\Delta \mathrm{p})$ & $\mathrm{B}(\Delta \mathrm{p})$ & $\mathrm{B}(\Delta \mathrm{p})$ \\
\hline Multiple Referral & $.22^{*}(.05)$ & $.34^{*}(.08)$ & .04 \\
Sponsor in Majority & $1.61^{* * *(.33)}$ & $1.44^{* * *}(.31)$ & $1.73^{* * *}(.35)$ \\
Seniority & .001 & $.074 * * *(.29)$ & .000 \\
No. of Co-Sponsors & $.004^{* *}(.05)$ & .003 & .005 \\
Percentage of Co-Sponsors & & & -.92 \\
$\quad$ from One Party & $-1.25^{* * *}(-.29)$ & $-1.92^{* * *}(-.38)$ & $2.47 * * *$ \\
Constant & $-2.08^{* * *}$ & $-2.22^{* * *}$ & 1222 \\
$N$ & 2649 & 1427 & $95.5 * * *$ \\
Model Chi-Square $(5$ df) & $175.0^{* * *}$ & $144.4^{* * *}$ & .14 \\
Pseudo R ${ }^{2}=$ & .12 & .17 & \\
Notes: The dependent variable is coded 1 if the bill received committee attention and 0 if ignored. \\
The modal category is $85.6 \%$ (ignored). ${ }^{*} \mathrm{p}<=.05 ; * * \mathrm{p}<=.01 ; * * * \mathrm{p}<=.001 . \Delta \mathrm{p}$ value on significant \\
variables shows the maximum impact.
\end{tabular}

Hence, this finding means that as the proportion of the co-sponsors from one party decreases, the higher the bill's chances of progression (hence, the negative sign).

Table 2 presents the results of a logit analysis of bill progression from hearing to committee report. In other words, of those bills that receive a committee hearing, this analysis attempts to explain why some such bills are reported to the floor while some are not. Here, we again note differences in the impact of multiple referral between the Democratic model of 1991-94 (similar to the overall results) and the Republican approach of 1995-98. In the case of Democratic control, multiply-referred bills are significantly less likely to be reported out of committee than are singly-referred bills. The maximum substantive impact at this stage is much greater than at the hearing stages. Multiple referral status increases a bill's chance of defeat by 26 perent. However, during Republican control, no such distinction emerges in the multi-variate context. While the sign is positive, indicating that multiplyreferred bills are more likely to progress, the variable falls well short of significance.

Finally, Table 3 shows the results of a logit analysis of bill progression from committee report to floor passage. Of those bills that were reported to the floor by committee, why do some pass on the floor while others fail? Here, the partisan control differences vanish. In the overall model, and under both Democratic and Republican control, multiply-referred bills are much less likely to pass the floor than single referrals. The substantive impact is 
Table 2. Logit Analysis of the Determinants of Bill Progression from Committee Hearing to Committee Reported, U.S. House

\begin{tabular}{|c|c|c|c|}
\hline Independent Variable & $\begin{array}{l}1991-98 \\
\mathrm{~B}(\Delta \mathrm{p})\end{array}$ & $\begin{array}{l}1991-94 \\
\text { В }(\Delta \mathrm{p})\end{array}$ & $\begin{array}{l}1995-98 \\
\text { В }(\Delta p)\end{array}$ \\
\hline Multiple Referral & $-1.14 * * *(-.26)$ & $-1.13 * * *(-.26)$ & .235 \\
\hline Sponsor in Majority & $1.14 * *(.26)$ & .321 & $1.92 * * *(.37)$ \\
\hline Seniority & $0.02 *(.10)$ & .021 & .025 \\
\hline No. of Co-Sponsors & .001 & .001 & .002 \\
\hline \multicolumn{4}{|l|}{ Percentage of Co-Sponsors } \\
\hline Constant & .66 & .480 & -1.81 \\
\hline$N$ & 381 & 121 & 160 \\
\hline Model Chi-Square (5 df) & $44.2 * * *$ & $19.9 * * *$ & $17.6 * * *$ \\
\hline Pseudo $\mathrm{R}^{2}=$ & .15 & .12 & .14 \\
\hline \multicolumn{4}{|c|}{$\begin{array}{l}\text { Notes: The dependent variable is coded } 1 \text { if the bill was reported by }>=1 \text { committee and } 0 \text { if not. } \\
\text { The modal category is } 65.1 \% \text { (reported). }{ }^{*} \mathrm{p}<=.05 ;{ }^{*} \mathrm{p}<=.01 ; * * \mathrm{p}<=.001 . \Delta \mathrm{p} \text { value on significant } \\
\text { variables shows the maximum impact. }\end{array}$} \\
\hline
\end{tabular}

Table 3. Logit Analysis of the Determinants of Bill Progression from Committee Reported to Floor Passage, U.S. House

\begin{tabular}{lccc}
\hline & $1991-98$ & $1991-94$ & $1995-98$ \\
Independent Variable & $\mathrm{B}(\Delta \mathrm{p})$ & $\mathrm{B}(\Delta \mathrm{p})$ & $\mathrm{B}(\Delta \mathrm{p})$ \\
\hline Multiple Referral & $-1.61^{* * *}(-.33)$ & $-1.92 * * *(-.37)$ & $-1.56 * *(-.33)$ \\
Sponsor in Majority & -0.97 & -1.18 & -20.2 \\
Seniority & 0.002 & -.002 & .002 \\
No. of Co-Sponsors & -0.004 & .000 & -.008 \\
Percentage of Co-Sponsors & & -1.72 & -1.29 \\
$\quad$ from One Party & $-1.83^{*}(-.37)$ & $4.49^{*}$ & 23.37 \\
Constant & $4.34^{* *}$ & 149 & 99 \\
$N$ & 248 & $21.4^{* * *}$ & $17.9 * * *$ \\
Model Chi-Square $(5 \mathrm{df})$ & $33.2^{* * *}$ & .23 & .25 \\
Pseudo $\mathrm{R}^{2}=$ & .19 & & \\
Notes: The dependent variable is coded 1 if the bill passed the floor and 0 if not. The modal category \\
is $77 \%$ (passed floor). ${ }^{*} \mathrm{p}<=.05 ; * * \mathrm{p}<=.01 ; * * * \mathrm{p}<=.001 . \Delta \mathrm{p}$ value on significant variables shows the \\
maximum impact.
\end{tabular}


quite strong-multiple referral status decreases a bill's chances of floor passage by well over 30 percent.

\section{Conclusion}

This study of the effect of multiple referral on the legislative process of the 1990s U.S. House expands in three important ways the existing research done on the use of the new technique in the 1970s and 1980s House. First of all, we find that the impact of multiple referral is conditional on the legislative stage being analyzed. Multiple referral status actually makes bills more likely to initially be heard in committee. The other three stages exhibit a very different impact. Multiple referral status hurts a bill's chances of success in the committee reported and floor passage stages. Finally, multiply referred bills are no more or less likely to be enacted into public law (of those passing the House) than singly-referred bills.

Secondly, our approach of analyzing the effect of multiple-referral status on bill progression by stage on only those bills surviving the previous stage (rather than as a percentage of all bills) demonstrates more clearly how hard it is to move multiply-referred bills through committee and the floor. Multiply referred bills are 25 percent less likely to be reported out of committee and 60 percent less likely to pass the floor than singly referred bills. Hence, the implications of the House reform appear more dramatic than previous literature has suggested.

Lastly, the Republican alterations to multiple referral in 1995 had a notable impact on the committee report stage of the legislative process. Whereas multiply-referred bills were much less likely to pass committee and go to the floor than were singly-referred bills under Democratic control from 1991-94, multiply-referred bills processed in committee under Republican control were more likely to advance to the floor than singly-referred bills. It appears that the Republican change that names a lead committee produces more cooperation, or at least less conflict, than the shared referral approach used prior.

\section{NOTES}

${ }^{1}$ We find an even higher percentage of bills (33.7\%) subject to multiple referral in our sample of five issue areas in the 1990s House.

${ }^{2}$ We focus exclusively on the House because Senate use of multiple referral, though long permitted under the Rules, occurs on less than $2 \%$ of bills. Davidson, Oleszek and Kephart wisely explain why this is so: "The Senate uses multiple referrals less frequently, in part because that body has other mechanisms for intercommittee coordination: overlapping committee memberships, for example, and a tradition of accommodating non-committee members through informal negotiations and floor amendments" $(1988,4)$. 
${ }^{3} \mathrm{We}$ also explored the possibility that the phenomenon was more than a simple dichotomy. That is, perhaps the effect of multiple referral varies along a continuum from 1 committee upward: the more committees, the harder it is to move bills forward. While significant, this measurement approach did not improve our explanatory power above beyond the simple dichotomy. This is probably due to the fact that the lion's share of multiply-referred bills goes to only two or three committees. Hence, not enough of a distribution obtains in order to justify a continuum.

${ }^{4}$ The five policy areas also nicely represent the three issue categories in Theodore Lowi's classic typology (1964): distributive, redistributive, and regulatory. Agriculture is distributive (e.g., specific crop supports) and redistributive (e.g., food stamps to the poor). Education is redistributive (e.g., Pell grants) and regulatory (e.g., federal funding to colleges and universities is contingent on obeying a battery of federal regulations). Health care policy is redistributive (Medicare) and regulatory (FDA drug approval). Environmental policy and telecommunications policy are regulatory. Moreover, two of the issue areas have a foreign as well as a domestic component (agriculture and telecommunications).

${ }^{5} \mathrm{We}$ feel that is important to include the first winnowing stage because it is the point at which the overwhelming majority $(85 \%)$ of bills falter. Most bills on Capitol Hill never see the light of day after initial referral to committee. Adding a public law stage to the analysis provides a role for the important final stage of the legislative process.

${ }^{6} \mathrm{We}$ expect majority member-sponsored bills, those sponsored by more senior members, measures with more co-sponsors, and measures with bi-partisan support to be more likely to succeed.

${ }^{7}$ For the public law stage, a non-finding for the multiple referral variable resulted. In addition, no others variables were significant and the model diagnostics were quite poor. Given that there is nothing to show in a table, we do not present a separate table for the public law stage of analysis.

\section{REFERENCES}

Baughman, John. 2006. Common Ground: Committee Politics in the U.S. House of Representatives. Stanford, CA: Stanford University Press.

Browne, William P. 1998. Groups, Interests, and U.S. Public Policy. Washington, DC: Georgetown University Press.

Congressional Information Service, Inc. 2003. Web searches conducted in October and November, 2003. CIS Congressional Universe: Bills. http://web.lexis-nexis.com/ congcomp.

Davidson, Roger H., Walter J. Oleszek, and Thomas Kephart. 1988. One Bill, Many Committees: Multiple Referrals in the U.S. House of Representatives. Legislative Studies Quarterly 13(1):3-28.

King, David C. 1997. Turf Wars: How Congressional Committees Claim Jurisdiction. Chicago: University of Chicago Press.

Oleszek, Walter, 1996. Congressional Procedures and the Policy Process, 4th ed. Washington, DC: Congressional Quarterly Press.

Rieselbach, Leroy N. 1994. Congressional Reform: The Changing Modern Congress. Washington, DC: Congressional Quarterly Press.

Schickler, Eric. 2001. Disjointed Pluralism: Institutional Innovation and the Development of the U.S. Congress. Princeton, NJ: Princeton University Press. 
Sinclair, Barbara. Unorthodox Lawmaking. Washington, DC: Congressional Quarterly Press.

Smith, Steven S. 1989. Call to Order: Floor Politics in the House and Senate. Washington, DC: Brookings.

Smith, Steven S., and Christopher J. Deering. 1990. Committees in Congress, 2nd ed. Washington, DC: Congressional Quarterly Press.

Stanley, Harold W., and Richard G. Niemi. 1994. Vital Statistics on American Politics, 4th ed. Washington, DC: Congressional Quarterly Press.

Young, Garry, and Joseph Cooper. 1993. Multiple Referral and the Transformation of House Decision Making. Pp. 211-234 in Congress Reconsidered, 5th ed., eds., Lawrence C. Dodd and Bruce I. Oppenheimer. Washington, DC: Congressional Quarterly Press. 